\title{
Saúde Mental em Tempos de Crise e Pandemia: Um Diálogo com Martín-Baró
}

\author{
Mental Health in Times of Crisis and Pandemic: A Dialogue with Martín-Baró \\ Salud Mental en Tiempos de Crisis y Pandemia: Un Diálogo con Martín-Baró
}

\author{
Pedro Henrique Antunes da Costa ${ }^{1}$ \\ Universidade de Brasilia (UnB) \\ Kíssila Teixeira Mendes \\ Universidade Federal de Juiz de Fora (UFJF)
}

\begin{abstract}
Resumo
O presente artigo é um exercício teórico-analítico sobre as implicações na/da saúde mental de uma conjuntura de crise(s) atravessada pela pandemia da covid-19; uma tentativa de compreender o que tal momento expressa e os possíveis encadeamentos em termos de saúde mental. Propõe-se um diálogo com Ignacio Martín-Baró, cuja análise psicossocial sobre a saúde mental no contexto de guerra civil de El Salvador pode contribuir ao exame da atual conjuntura num sentido histórico, extraindo subsídios necessários para a construção de outra realidade. Para isso, primeiramente, resgatamos o conceito de saúde mental de Martín-Baró, situando-a como uma produção humana, no âmbito das relações sociais, circunscrita à sociabilidade capitalista. Posteriormente, escrutinamos algumas das implicações do cenário de pandemia para a saúde mental, sinalizando algumas saídas. Por fim, realizamos uma síntese dos argumentos.

Palavras-chave: saúde mental, pandemias, coronavírus, capitalismo
\end{abstract}

\begin{abstract}
The article is a theoretical-analytical exercise about the implications on mental health of a crisis' conjuncture crossed by the covid-19 pandemic. An attempt to understand the expressions of the moment and possible linkages in terms of mental health. We proposed a dialogue with Ignacio Martín-Baró, whose psychosocial analysis on mental health in the context of El Salvador's civil war can contribute to examining the current situation in a historical sense, extracting the necessary subsidies for the construction of another reality. For that, first, we rescued Martín-Barós concept of mental health, placing it as a human production, within the scope of social relations, limited to capitalist sociability. Subsequently, we scrutinized some of the implications of the pandemic scenario for mental health, indicating some paths. Finally, we perform a summary of the arguments.
\end{abstract}

Keywords: mental health, pandemics, coronavirus, capitalism

\section{Resumen}

El artículo es un ejercicio teórico-analítico sobre las implicaciones para la salud mental de una coyuntura de crisis atravesada por la pandemia de covid-19; un intento de comprender qué ese momento expresa y los posibles vínculos con la salud mental. Se propone un diálogo con Ignacio Martín-Baró, cuyo análisis psicosocial sobre la salud mental en el contexto de la guerra civil de El Salvador puede contribuir a examinar la situación actual en un sentido histórico, extrayendo subsidios necesarios para la construcción de otra realidad. Para eso, primero, rescatamos el concepto de salud mental de Martín-Baró, colocándolo como una producción humana en las relaciones sociales, limitada a la sociabilidad capitalista. Posteriormente, analizamos algunas de las implicaciones del escenario de la pandemia para la salud mental, señalando algunas salidas. Finalmente, realizamos un resumen de los argumentos.

Palabras clave: salud mental, pandemias, coronavirus, capitalismo

\footnotetext{
${ }^{1}$ Endereço de contato: Pedro Henrique Antunes da Costa, SQN 407, Bloco E, Sala 204, Asa Norte, Brasília. E-mail: phantunes.costa@gmail.com
} 


\section{Introdução}

O presente artigo é um exercício teórico-analítico acerca das implicações na/da saúde mental de uma conjuntura de crise(s) atravessada pela pandemia da covid-19 (ocasionada pelo vírus Sars-CoV-2 ou, no senso comum, coronavírus); uma tentativa de compreender o que tal momento expressa e os possíveis encadeamentos em termos de saúde mental. Para isso, propõe-se um diálogo com Ignácio Martín-Baró, cuja análise psicossocial sobre a saúde mental no contexto de guerra civil de El Salvador pode contribuir ao exame da atual conjuntura num sentido histórico, extraindo desse escrutínio subsídios necessários para a construção de outra realidade.

Martín-Baró (1942-1989) foi um padre jesuíta, filósofo, teólogo e psicólogo nascido na Espanha, mas que viveu a maior parte de sua vida em El Salvador, naturalizando-se salvadorenho. Dentro de suas diversas contribuições, por meio de um projeto ético-político de psicologia que refletia ele próprio e sua práxis, destacamos: as críticas ao saber tradicional da psicologia e campo psi no geral ante a compreensão do indivíduo, devendo ser entendido em sua concretude histórica e social; e a necessidade de um horizonte de transformação radical de nossa sociabilidade, forjando um novo ser humano - e sendo forjado por ele (Lacerda Júnior, 2017). Foi assassinado por um esquadrão de elite do exército salvadorenho em 16 de novembro de 1989, braço repressivo do governo do presidente Alfredo Cristiani - representante das oligarquias locais em conluio com o imperialismo estadunidense -, na Universidade Centro-Americana, onde trabalhava, junto de outros cinco companheiros jesuítas, uma funcionária da universidade e sua filha (Lacerda Júnior, 2017).

Em termos metodológicos, o diálogo proposto com o autor segue um movimento de resgate de suas formulações sobre saúde mental, tomando nossa realidade como parâmetro. Um retorno às suas reflexões, que, a despeito do contexto específico, mostram-se ainda atuais e continuarão enquanto continuarmos nessa sociabilidade e, mais especificamente, em um país e continente dependentes, que não romperam com sua constituição colonizada. Do mesmo modo, é um exercício imaginativo de retirá-lo de seu túmulo, convidando-o a pensar conosco o presente, trazendo alguns pensadores em que Martín-Baró se fundamentava, como o seu diálogo com a tradição marxista, e, nisso, atualizar seu pensamento, dando continuidade à sua práxis.

A partir do exposto, dividimos o texto em três partes. Na primeira, resgatamos o conceito de saúde mental de Martín-Baró (1973; 1984/2017a), situando-a como uma produção humana, no âmbito das relações sociais, circunscrita à sociabilidade capitalista. Posteriormente, escrutinamos algumas das implicações do cenário de pandemia para a saúde mental, com os dados conjunturais interpretados à luz do pensamento do autor. Na impossibilidade de trazer a totalidade de sua produção, selecionamos algumas de suas principais obras (MartínBaró, 1980/2017b; 1983/2017c; 1986/2011; 1996). Nesse ínterim, sinalizamos algumas saídas. Por fim, realizamos uma síntese dos argumentos, com provocações para o presente e o futuro.

\section{A Saúde Mental na Tragédia}

Como ser humano, é impossível não se ter saúde mental. Se, para fazer história, é preciso estar vivo, para ter saúde mental, também; da mesma forma, para estar vivo, é preciso de 
saúde mental. A saúde mental diz respeito ao ser humano, à sua constituição e à sua práxis no mundo; é um "caráter básico das relações humanas" (Martín-Baró, 1984/2017a, p. 253). Mesmo uma pessoa com depressão, com os ditos transtornos mentais, em sofrimento etc., continua a ter saúde mental, só que uma saúde mental combalida, adoecida. Assim como uma pessoa com diabetes ou hipertensão continua a ter saúde, mas uma saúde também atravessada por doenças. Saúde se refere ao ser como totalidade e como este se faz no mundo, não à doença. Sendo assim, o entendimento sobre como ela é produzida, qual é a sua constituição e o que ela exprime implica uma análise radical sobre como tal ser, igualmente, é forjado. A própria etimologia do termo radical já deixa claro: ir à raiz dos problemas. $\mathrm{E}$ como Marx (1844/2010) certa vez explicitou, a raiz do ser humano é o próprio ser humano.

Contudo, tal compreensão sobre a saúde mental não é consensual. Não obstante, as concepções de ser humano são variadas, com tudo isso gerando uma pluralidade de entendimentos. Para Martín-Baró (1984/2017a), as concepções hegemônicas sobre saúde mental podem ser divididas em dois agrupamentos, não necessariamente excludentes: (a) sinônimo ou ausência de transtornos mentais; ou (b) um funcionamento adequado do organismo.

No primeiro caso, saúde mental orbita em torno da patologia (seja pela sua afirmação, seja pela negação). Nesses termos, é comum pensar que ter saúde mental é não expressar nenhuma patologia, nenhum sofrimento; e o inverso também seria verdadeiro: quem tem algum transtorno não tem saúde mental. Por exemplo, só tem saúde mental quem não é diagnosticado com nenhum transtorno mental ou quem não está sofrendo. Sobre esse segundo ponto, cabe a pergunta: quem não está ou já não sofreu? Então, quem foi diagnosticado com depressão, transtorno de ansiedade, esquizofrenia etc. é desprovido de saúde mental? Conforme introduzido, se pensarmos na saúde mental como produção humana, não. Afinal, ela se refere ao indivíduo e como ele se produz (e a produz) nessa sociedade.

No segundo agrupamento de concepções hegemônicas, segundo Martín-Baró, além de impregnado numa lógica funcionalista, fazendo-nos questionar o que seria um bom funcionamento e, mais, o que significaria esse bom funcionamento, o "mental" é um mero espeIhamento do orgânico, sendo entendido nos mesmos moldes da fisiologia. Porém, caberia a indagação de que um "mau funcionamento mental", por exemplo, a loucura, historicamente vista como anormalidade e, por conseguinte, adquirindo sentido negativo e pejorativo, seria caracterizada, ao contrário, como um comportamento normal em condições anormais (Martín-Baró, 1973).

A despeito das especificidades das concepções anteriormente citadas, em ambos os casos, saúde mental é entendida como atributo individual; algo que "brota" do indivíduo, de sua mente ou do seu cérebro; que diz muito (ou quase tudo) de si e pouco do mundo em qual este ser e sua saúde mental se criam. Opondo-se à hegemonia na área, conforme Martín-Baró (1984/2017a), ainda que a saúde mental de cada ser seja única, dizendo da própria singularidade deste, não há algo como uma saúde mental privativa, individualizada, um estado individual; muito menos essa se reduz a um fenômeno orgânico e/ou psicológico, por mais que constituída por fatores orgânicos e psicológicos. Portanto, em vez de uma "encarnação do funcionamento individual interno", é a "materialização, na pessoa ou no grupo, do caráter humanizador ou alienante de uma estrutura de relações históricas" (p. 251).

Parte-se de uma relação dialética indivíduo-sociedade, com a saúde mental nesse interregno. Por um lado, é evitado um individualismo que pensa ser suficiente - e possível - abrir 
mentes (ou cérebros) para encontrar a saúde mental e tratar dela; por outro, um sociologismo, como se essa fosse um mero produto societário que adentra nas mentes dos indivíduos e deles se apossam.

Ao postular que a "distribuição da saúde mental está vinculada com a distribuição da riqueza produzida no país" (Martín-Baró, 1980/2017b, p. 29), o autor nos dá um indicativo de que saúde mental deve ser compreendida como uma produção humana, que remete a este ser e suas condições de produção e reprodução; o resultante de como este ser vive, como pensa, como se alimenta, onde mora, dorme, enfim, como se relaciona consigo, os outros e o mundo. Dessa forma, ao se referir a este ser, remete à sua concretude de constituição; diz respeito ao onde e como nos fazemos: numa ordem social antagônica, cujo antagonismo central "capital-trabalho" produz todo um conjunto de desigualdades que afetam esse fazimento humano e que se imbricam. Inclusive, poderíamos - e deveríamos - aprofundar a análise de Martín-Baró: se a distribuição da saúde mental se relaciona com a da riqueza produzida no país (e no mundo), o que faz com que tal riqueza socialmente produzida seja concentrada? Ora, se não é tal antagonismo de classes, que se consubstancia a outros, como os de raça, etnia e gênero, por exemplo, formando um todo coeso de exploração e opressão das maiorias populares. Indo ainda mais além, no que tal antagonismo está fundado, senão na propriedade privada que, historicamente, significou o ato de possessão de alguns poucos e a consequente despossessão do restante da humanidade? A maioria que, despossuída dos meios para sua sobrevivência, é compelida a vender sua força de trabalho, tornando-a mercadoria e, nisso, sendo apropriada junto dela por outrem; torna-se, portanto, mercantilizada, tal como suas necessidades. Um indivíduo que, ao ser alienado, apartado de sua atividade, também será do fruto de seu trabalho, dos outros e de si próprio; uma sociedade "onde cada um é estranho de si e todos são estranhos entre si" (Marx, 1846/2006, p. 44).

Aliás, a própria fragmentação entre saúde e saúde mental, como se houvesse uma separação entre o corpo físico e o corpo mental, ao invés de um todo, o ser como uma totalidade múltipla, contraditória - circunscrita a outras mais abrangentes e à própria totalidade social -, vem a indicar que, além de cindido daquilo que produz, da sua atividade, dos outros e de si, o próprio ser é cindido em dois, sendo, no máximo, a soma das partes.

Dessa forma,

Se a base da saúde mental de um povo encontra-se na existência de relações humanizadoras, de vínculos coletivos nos quais e pelos quais se afirma a humanidade pessoal de cada um e não se nega a realidade de ninguém, então a construção de uma sociedade nova ou, pelo menos, melhor e mais justa, não é somente um problema econômico e político; é também, e por princípio, um problema de saúde mental (Martín-Baró, 1984/2017a, p. 267).

Saúde mental é, portanto, algo demasiadamente complexo e importante - afinal, diz respeito à vida - para ser tratado apenas por especialistas do campo psi, suas ciências e profissões. Conforme Martín-Baró (1973, p. 206), "esta nuestra ciencia quizá tenga que dejar de ser no sólo esta ciencia, sino dejar de ser nuestra". Igualmente, encontram-se limitadas a priori as técnicas, procedimentos, abordagens etc. desse campo, a despeito da importância que possam vir a ter - o que, por outro lado, nos leva a refletir sobre o seu mandato histórico de controle, ajustamento, em suma, de manutenção da ordem; como a clínica, por exemplo, 
substituiu e pode substituir a prisão, e as instituições tradicionais de "tratamento" em saúde mental foram e são fábricas de enfermidades e enfermos (Martín-Baró, 1973).

Na realidade, saúde mental não é exclusividade do campo psi, mesmo que, num marco de divisão do trabalho, ela seja retirada do todo que a constitui, sendo alvo de disciplinas e profissões particularizadas. Por exemplo, um economista e suas propostas de contrarreforma neoliberais, que venalizam ainda mais as condições de vida das maiorias populares, age, mesmo sem saber, sobre as saúdes mentais destas; provoca uma precarização objetivo-subjetiva. O preço do salário mínimo e do gás de cozinha, o desemprego, a pobreza, entre tantos outros exemplos, em suas múltiplas determinações de classe raça, etnia, gênero etc., são problemas também de saúde mental, pois impactam na forma como vivemos e, portanto, como nos sentimos, conforme Martín-Baró (1984/2017a) postulou em suas análises. Pensar que a saúde mental é "tratada" nos moldes tradicionais da psicologia, psiquiatria e psicanálise somente nos diz das incoerentes e descaracterizantes compreensões e práticas hegemônicas sobre a saúde mental. Isso não significa que economistas devam atuar como psicólogos, mas que devem ter consciência das consequências concretas de suas ações. Do mesmo modo para os trabalhadores do campo psi, aliado ao fato de que devem buscar conhecimentos de outros complexos do saber-fazer.

Não é possível separar saúde mental de nossa ordem social (Martín-Baró, 1984/2017a); não se trata de saúde mental num vazio histórico, como algo abstrato, uma suposta essência humana igualmente idealizada e estática. Ao se tratar de seres humanos em suas concretudes históricas, que se fazem - e, nisso, produzem a história - em determinadas condições e circunstâncias preestabelecidas, não correspondentes às suas necessidades (Marx, 1851/2011), igualmente, é produzida nossa saúde, seja ela física, seja ela mental; tal como o ser ao qual se remete, produto e produtora. Trata-se, pois, da saúde mental no/do capitalismo. No capitalismo hodierno, no seu atual estágio de desenvolvimento, cuja razão-de-ser é o neoliberalismo (Dardot \& Laval, 2016), podendo ser entendido pelas seguintes características: crises econômicas que, nas suas "tragédias", contribuem para que o $1 \%$ mais rico detenha mais que o dobro da riqueza de 6,9 bilhões de pessoas (OXFAM Brasil, 2020); o processo de destruição exponencial da natureza; crises humanitárias; a ascensão de atores, discursos e práticas fascistas (algumas incorporadas por regimes políticos); guerras que não cessam, entre outras. Parece que ou destruímos esse sistema, ou ele, em seu desenvolvimento destrutivo, acaba por destruir a humanidade.

A covid-19 e o coronavírus são, portanto, "apenas" o "menu" do dia, os personagens principais do momento nessa saga trágica chamada capitalismo. No fundo, sem tanto destaque, estão inúmeros outros figurantes, cujo papel figurativo diz muito mais sobre nossa incapacidade de enxergar a trama como um todo; todos também "vilões", muito mais talentosos que os personagens principais e com igual ou superior importância em termos de destruição. Um drama que, na tentativa de ocultar seu próprio enredo, apresenta-se como comédia, um humor mórbido, de péssimo gosto. A saúde mental no/do capitalismo é a saúde mental na/ da tragédia; como uma de suas expressões trágicas; uma saúde mental trágica, pois.

\section{As Crises, os Vírus e a Saúde Mental}

Na esteira das reflexões, o capitalismo se faz de crises; faz-se nas crises. Nelas, ele se redinamiza, atualiza-se, para se manter, mesmo fazendo concessões; uma restauração na re- 
novação (Paulo Netto, 2012). A pandemia da covid-19, apesar de entendida como algo em si, um fator isolado, mascarando o colapso sistêmico, é uma das facetas do colapso sistêmico.

Conforme postulou Martín-Baró (1973), se a loucura pode ser entendida como uma expressão normal de uma sociedade e/ou condição de anormalidade, ante a condição de excepcionalidade e anormalidade vividas, espera-se a produção de mais sofrimento como resposta normal. Não se trata aqui de uma aceitação ou apologia à loucura ou aos quadros de sofrimento mental, de negação ou pouco caso do que representa este sofrimento. Pelo contrário, que o repúdio a isso deve partir de uma análise realista e crítica da saúde mental em sua concretude histórica.

O quadro de uma crise que é econômica, política, social e humanitária é agravado por uma pandemia que lhe agrega mais uma faceta crítica, a de uma crise sanitária, intensificando todas as outras. Remetendo ao histórico de desenvolvimento do capitalismo, observamos inúmeras e contínuas crises, o que nos permite concluir que este sistema gera suas próprias contradições, tendo as crises como momento de amplificação destas, incorrendo em "situações-limite", em que "a própria viabilidade e sobrevivências históricas de um povo estão em questão" (Martín-Baró, 1984/2017a). Vimos que, antes da covid-19, o panorama era de uma crise de superprodução e continuidade da retração econômica, com piora generalizada nas condições de vida das maiorias populares (OXFAM Brasil, 2020); a continuidade, em uma forma aguda, da crise estrutural, sistêmica do capitalismo (Paulo Netto, 2012). É nesse interregno que surge o coronavírus e a pandemia da covid-19. Não se trata, pois, de uma crise do coronavírus e da covid-19, mas uma crise do capitalismo, aguçada pelo coronavírus e pela covid-19. Assim, tende-se a intensificar também o sofrimento, como expressão da própria agudização das insuficiências e debilidades societárias; ou seja, uma saúde mental mais precária porque se tem uma vida ainda mais precarizada.

Nisso, devemos considerar que as implicações da presente conjuntura de crise e pandemia para a saúde mental não atingem todos(as) de maneira indiferenciada, como Martín-Baró (1984/2017a) observou na guerra civil em El Salvador. Ao analisar a realidade salvadorenha, o autor apreende três elementos constitutivos que se retroalimentam e que configurariam a guerra, com implicações à saúde mental: 1) a violência sistêmica; 2) a polarização social; e 3) a institucionalização da mentira. A partir dessa caracterização, questionamos: quando, em nossa história particular periférica, colonial e dependente - tal como El Salvador -, não vivemos guerras constantes? Tal contestação vale ainda mais para o presente momento, em que todos os três elementos se aguçam: há o recrudescimento da violência; a intensificação da polarização - não no sentido da fissura que a origina, o antagonismo de classes, mas de uma disputa entre indivíduos, muitos deles da mesma classe dominada, explorada e oprimida; e o fomento ainda maior da mentira.

Nessa direção, um exercício inicial de abstração, mas como forma de captar o real concreto transformando-o em real pensado, refere-se à consideração das singularidades dos indivíduos, as quais se atrelam, contudo, à totalidade social e, portanto, expressam-na e a conformam, mediadas pelas particularidades sociais. Assim, as mudanças exigidas nas vidas de muitos, como o isolamento físico, a quarentena etc. e suas implicações à saúde mental, devem ser pensadas nas/pelas condições concretas de vida; desde suas condições singulares, dependendo da vivência de cada um, mas que não se trata de problema individual. Mesmo que tragam desafios adicionais, pelo fato de serem novidades em nossas rotinas, 
para alguns serão ainda mais deletérias - enquanto a classe dominante continuar a lucrar com as misérias - do sistema e do momento. Ao passo que alguns(mas) da classe trabaIhadora têm condições de realizá-las, o que não se trata de privilégio, mas de um direito conquistado, a outros(as) tantos(as) esses mesmos direitos são negados. O que dizer, então, dos reais privilegiados da classe dominante? Entretanto, mesmo estes podem ser atingidos deleteriamente, "como se somente os trabalhadores definhassem sob as atuais condições sociais, ao passo que, para o restante da sociedade, o mundo tal como existe fosse o melhor dos mundos" (Marx, 1846/2006, p. 22).

Em decorrência da reestruturação produtiva do capitalismo nos anos 1960/1970 como resposta à sua crise sistêmica, estrutural, trazendo como saída os predicados do neoliberalismo - que passa a ser sua razão-de-ser -, vemos o recrudescimento de uma ofensiva contra a classe trabalhadora (e, portanto, contra seus direitos-conquistas) (Paulo Netto, 2012). Entre as várias ações, temos um número crescente de pessoas no desemprego, compelidas à informalidade, totalmente desprotegidas pelo colchão protetivo dos direitos trabalhistas; estes, por sua vez, têm sido mais sucateados e suprimidos na continuidade dessa ofensiva via contrarreformas ad eternum (trabalhista, previdenciária etc.). A estes condenados do asfalto (numa alusão aos condenados da terra de Frantz Fanon, 1961/2015, influência notória no pensamento de Martín-Baró), sob a ideologia do empreendedorismo, a quem se somam os condenados da terra, não se permite nenhum tipo de desvio da normalidade, tendo de lidar agora não apenas com a precariedade intrínseca a ela, mas com o risco de contaminação, adoecimento e morte, desemprego, perda de salário, diminuição da renda etc. Para piorar, suas angústias e sofrimento costumam ser silenciados pelo ronco de suas barrigas e choros de fome de seus filhos, reforçando que o não diagnóstico de transtornos mentais não é sinônimo de ausência de sofrimento - com o inverso também sendo verdadeiro, dada a lógica de (psico)patologização e medicalização da vida reinantes.

Alia-se a isso todas as iniquidades de acesso aos sistemas de saúde e políticas sociais. Historicamente sucateadas, tais políticas constituem uma das frentes de retrocessos e desmonte do atual estágio de desenvolvimento do capitalismo neoliberal, exprimindo o ataque espoliativo do capital à classe trabalhadora e ao Estado, por meio do saqueamento do fundo público (Paulo Netto, 2012). É, inclusive, a partir dessa precarização e desse desmonte do sistema público de saúde, das políticas de assistência social, da insuficiência de verbas para pesquisas, entre outras ações que compõem o vírus do capitalismo - ainda mais virulento em suma mutação neoliberal -, aliadas às nossas próprias estruturas antagônicas e processo formativo desigual, que a covid-19 se espraia e passa a ser ainda mais letal; a venalidade e capacidade destrutiva de um sistema viral intensificam a letalidade dos vírus que nele surgem.

A despeito do que se pode pensar, o coronavírus não é democrático. Mesmo que tenha se expandido e afetado pessoas de classes, raças, etnias, gêneros e sexualidades distintas, mas que são igualmente humanas, sua transmissão, o adoecimento e as consequências objetivo-subjetivas e físico-mentais exprimem nossas abruptas e inaceitáveis diferenças na concretização dessa humanidade; ou seja, a não correspondência entre a humanidade formal, em abstrato, e a concreta. Nisso, evidencia-se que o que nos diferencia socialmente são construções sociais, as quais não só podem como devem ser transformadas. Portanto, um primeiro aspecto a ser considerado no entendimento das implicações da conjuntura para a 
saúde mental são os nossos antagonismos sociais, de classe (Martín-Baró, 1984/2017), raça, etnia e gênero, que estruturam nossa dinâmica social. Nada mais trágico e abominavelmente esclarecedor do que uma das primeiras mortes por coronavírus registradas e publicizadas, no país, ter sido de uma empregada doméstica, negra e periférica, cujos patrões voltaram contaminados de suas férias no exterior e, mesmo assim, ela teve de continuar trabalhando; de que o coronavírus é mais letal entre negros(as) (Batista et al., 2020) e nos povos originários (Instituto Socioambiental, 2020). Igualmente elucidativo foi o pronto socorro aos bancos na casa dos trilhões, sem questionamentos, enquanto fica o martírio das maiorias populares em acessarem suas migalhas - quando isso é possível. O processo de "gentrificação", periferização e interiorização mais recente do vírus e da doença evidencia a impossibilidade dos(as) trabalhadores(as) mais subalternizados se manterem em isolamento, incorrendo em maior exposição. Soma-se a isso as dificuldades de acesso à testagem e ao tratamento nessa parcela populacional, aumentando as taxas de mortalidade e, ao mesmo tempo, acarretando perdas de renda e desemprego (Barbosa, Prates, \& Meireles, 2020). Poderíamos dar mais exemplos, mas acreditamos que o exercício já foi suficiente.

Cabe apenas levantar a atenção necessária aos impactos subjetivos da pandemia, mais especificamente da forma como ela vem sendo gerenciada, articulados às implicações objetivas. Se tais grupos sociais e parcelas populacionais são os mais afetados objetivamente, é coerente pressupor que também serão mais afetados subjetivamente, mesmo que todas essas implicações deletérias possam se generalizar - considerando as singularidades dos indivíduos e mediações das particularidades que cimentam a vida social. Com isso, novamente afirmamos a relação dialética objetivo-subjetivo do movimento do real.

Um segundo ponto diz respeito ao caráter virulento de nossa sociedade. Utilizando a terminologia epidemiológica-médica como metáfora, nossas endemias não só de doenças, mas de mazelas sociais referentes a um modo de produção pautado na exploração e opressão e que, em nossa formação particular, se desenvolveu na/pela colonização escravocrata; um capitalismo dependente, subordinado às economias centrais do globo (Fernandes, 1975/2006; Marini, 1973/2017). O enfrentamento ao coronavírus não deve solapar as atenções com as nossas urgências sociais tratadas paliativamente, a conta-gotas - quando tratadas; ou seja, não deveria fazer com que esqueçamos daquilo que historicamente e cotidianamente naturalizamos. Até porque, como demonstramos, a covid-19 é atravessada por essas mazelas, ao mesmo tempo que as intensifica. Tendemos a nos espantar com elas, como se surgissem do nada no presente momento, mas o que aconteceu foi a sua agudização ou maior evidenciação numa situação de excepcionalidade.

Também aliado aos demais, o terceiro ponto se refere ao fato de que as exigências circunstanciais, novamente, de isolamento, quarentena etc. - e que talvez perdurem durante um tempo significativo, tratando-se do novo normal de nossa convivência e dinâmica de vida no curto e médio prazo - são hipérboles de nossa tessitura social; idem para o sofrimento e precarização objetivo-subjetiva da vida e, portanto, da saúde mental. Pautada na/ pela individualização e isolamento, numa concepção essencialista de ser humano individualizante, fragmentado, autorrealizável e, portanto, egoico, temos nas medidas necessárias à diminuição e ao retardamento do contágio da covid-19 um superlativo dos fundamentos de nossa sociedade. Um "novo", cuja novidade está na dosagem, que está enraizado em nosso tecido social e dinâmica de vida de alienação uns dos outros e, portanto, de si, conforme 
já discutimos. A contradição reside no fato de que o isolamento e a individualização em excesso fazem mal ao sistema, enquanto as medidas só fazem mal aos indivíduos, não há motivo para se preocupar. Valendo-nos de uma metáfora médica, não é importante atacar o metabolismo social imanentemente virulento, isto é, nossa formação social desigual, exploratório-opressiva, junto do enfrentamento ao coronavírus?

Nosso intuito, conforme já explicitamos, não é o de fazer um profundo esquadrinhamento do presente cenário, mas consideramos que o coronavírus desvela para nós algumas contradições que não são dele, do vírus e da doença propriamente ditos, mas da sociedade na qual tal vírus e doença se materializam. Primeiro, o coronavírus evidencia quem, de fato, move essa grande engrenagem e que, portanto, se parar, ela desmonta: os(as) trabalhadores(as). Segundo, revela, de maneira ainda mais cristalina, a mediocridade de uma sociedade que não consegue se organizar para combater um vírus, cuidar dos seus, sem ser regida pelo imperativo do lucro ante as vidas. Se tal sociedade não nos serve, no sentido de não se voltar para o atendimento de nossas necessidades, também não nos presta; precisamos de outra. Terceiro, demonstra a incongruência dessa sociabilidade pautada na/pela individualização e a nossa própria condição de seres sociais; a incompatibilidade entre como somos concebidos, numa essencialidade genérica, abstrata, e possibilitados de ser no/pelo plano formal, e como somos (e podemos ser) de fato. Em quarto lugar, as medidas para enfrentar a pandemia da covid-19 tomadas no globo - com exceção de países como o Brasil - se estranham, mesmo que sem romper com a lógica do lucro em detrimento das vidas, da liberdade plena do mercado e sanha acumulativa do capital (Barbosa et al., 2020), significando uma brecha para a reorientação da órbita econômico-política do sistema-mundo, abrindo possibilidades de fissuras. A despeito do pronto atendimento às necessidades parasitárias do capital financeiro, ações como o maior investimento estatal nas políticas sociais, garantia de renda e emprego também pelo Estado, estatização de indústrias e fábricas para a produção de insumos médicos, entre outras, quebrando com o dogmatismo fiscalista e receituário neoliberal, mesmo que tomadas tardiamente, indicam que tudo o que nos haviam dito parece ter sido uma grande mentira.

Se nos querem - ainda mais - isolados, que este isolamento seja apenas físico e dele fomentemos solidariedade; solidariedade como oposição a uma lógica de vida que, como vimos, nos aparta e individualiza; como resgate de nossa humanidade desumanizada. De maneira bastante elucidativa, a pandemia do coronavírus vem para nos mostrar que nós nos fazemos uns com os outros, nas relações sociais, sendo a saúde mental resultante desse processo, como atestou Martín-Baró (1984/2017a); que nossas ações, independentemente de serem conscientes, impactam na vida de tantos outros e voltam para nós mesmos. Solidariedade como responsabilização, não num sentido de autoculpabilização; um antagonismo à lógica de individualização que reflete no controle do outro e de si. Um movimento de se afetar pelo outro e se implicar com ele; um outro que também sou eu, que está contido em mim, numa relação dialética. E não quaisquer outros(as), mas as maiorias populares e, nelas, aqueles e aquelas mais vulneráveis, com necessidades mais prementes, pois se encontram em realidades mais emergenciais e/ou ultrajantes. Até porque, se as relações sociais são fundadas em antagonismos, ao me relacionar com outro indivíduo, acabo por me relacionar com ele enquanto materialização e representação singular de determinada classe social, do seu imbricamento racial, étnico e de gênero etc. Conforme Marx (1847/2017, p. 93/94), a 
sociedade é vista como conjunto das "relações sociais fundadas no antagonismo das classes. Essas relações não são relações do indivíduo com o indivíduo, mas do operário com o capitalista, do arrendatário com o proprietário fundiário etc. Suprimidas essas relações, estará suprimida a sociedade (Marx, 1847/2017, pp. 93-94). Ao antagonismo de classes, engendramos outros antagonismos também estruturantes de nossa sociedade, os de raça, etnia, gênero e sexualidade. Portanto, uma solidariedade ativa de classe, raça, etnia e gênero.

O próprio isolamento físico daqueles(as) a que é possível tal movimento é uma forma solidária de não contribuir para a contaminação dos que não têm essa permissão; o cuidado de si como cuidado do outro - em especial, dos(as) impossibilitados de se cuidarem como necessitam - e vice-versa. Um meio, aliás, para que, no longo prazo, tal direito não seja apenas de uns, mas de todos, implicando a reversão dos ataques e retrocessos da ofensiva do capital ao trabalhador, como forma de sugar ainda mais dele os remédios para sua doença crônica - adoecendo e fatalizando sua "fonte de vida"; um capital cada vez mais parasitário.

Temos uma oportunidade, infelizmente no aguçamento trágico de nossa sociedade, de, por meio da solidariedade, engendrarmos outras maneiras de nos relacionarmos uns com os outros, com as coisas e, nisso, com nós próprios enquanto humanidade; de produzir saúde mental, mesmo num contexto de sofrimento. Entretanto, é importante não se pautar em uma narrativa romântica sobre o momento, que descortina o velho individualismo. Embora o cuidar de si seja fundamental, trata-se aqui do entendimento - e ação - de que a proteção da minha saúde mental requer a proteção da saúde mental de todos(as). Mais, de que uma saúde mental que expresse nossa humanidade, não a negação desta, requer luta coletiva pela construção de um novo mundo e, nesse processo, de novo ser humano. Como dizia uma pichação de muro da Inglaterra que circulou nas redes sociais, a qual traduzimos: capitalismo é o vírus, solidariedade é a cura. Solidariedade pode ser uma arma a se lançar contra esse sistema virulento, cronicamente adoecido e adoecedor.

A pandemia do coronavírus como um dos vírus desse sistema, uma das doenças ou episódios agudos de um sociometabolismo cronicamente doente e adoecedor (aguçando outras de suas patologias e sendo aguçada por elas) e que supomos avançar a um estágio terminal, aponta para o fracasso de este se manter, mas sob o custo de sua população - mais especificamente, o grosso daqueles que, nesse processo, são explorados e oprimidos; a custo deles(as) como um todo e, assim, de suas saúdes mentais. A falácia neoliberal, a quem tudo se privatiza, demonstra que o privado é político e que a saída está na socialização, não do vírus que adoece, mas de prevenção e soluções a ele, o que significa socializar o que o ser humano produz, devolvendo o próprio a si; voltar-se para o atendimento das necessidades humanas. Todavia, a exposição da falácia neoliberal é, antes de tudo, a crítica ao capitalismo que tem nela sua razão-de-ser contemporânea. Ao mesmo tempo, a demonstração de tal fracasso sistêmico diz do seu sucesso: de se manter, a despeito de tudo isso.

Assentamo-nos no realismo crítico baroniano, que se opõe a uma concepção positivista e a um idealismo metodológico descaracterizantes do movimento do real. Movimento, por sua vez, que traz consigo o negativo, a dialética do negativo: a crise, que, em sua tragicidade aguçada da própria tragédia sistêmica, traz e indica a sua negação e, nisso, a possibilidade de sua superação. Por mais que se deparar com o real possa ser impactante - e a pergunta a ser feita é por que em determinado momento deixamos de nos impactar -, é somente nesse/por esse confrontamento, dessa dinâmica da e para a realidade, que se permite não 
apenas compreendê-la, mas modificá-la. Por isso a importância da solidariedade até mesmo como forma de prevenir ou conter o pânico que abrolha nesses momentos e paralisa; a fuga da imobilização, por um lado, e, por outro, da super-responsabilização, que tendem a se retroalimentar, ao invés de se oporem. Um realismo crítico que implica numa utopia crítica, pois a confrontação com o real requer sua transformação; a produção de um novo horizonte a partir de uma nova práxis (Martín-Baró, 1986/2011).

Ao historicizar o desenvolvimento da Psicologia Social, Martín-Baró (1983/2017c) atesta que dois grandes questionamentos que orientaram sua constituição foram: O que mantém as pessoas unidas na ordem social estabelecida? O que integra as pessoas na ordem social? A despeito das especificidades de cada um, observemos como a análise reduz-se ao(s) indivíduo(s). Em ambos os casos, a ordem está dada, não há o que se fazer, cabendo a nós entendermos o que une tais seres nela, a ela, o que os integra e como são integrados. Poderíamos reformular tais questionamentos sem modificar radicalmente seus sentidos, mas ao mesmo tempo explicitando seu caráter reificador, ao perguntarmos: O que mantém as pessoas unidas ou as integra na ordem social - apesar dessa ordem social? O que ordena as pessoas àl na (des)ordem social?

Trazendo para a realidade presente, não exclusiva à Psicologia Social ou qualquer campo do saber-fazer, isso significaria questionarmos o que une e integra as pessoas nessa ordem que aprofunda sua condição barbarizante. Será que o que queremos é unir as pessoas ou integrá-las a uma sociabilidade como essa? Queremos retomar a normalidade que é, justamente, o problema? Portanto, a conjuntura atual, despida de seus véus mistificadores, vem para nos indicar que a pergunta necessária é aquela que Martín-Baró (1983/2017c) já havia questionado acerca da Psicologia Social: O que liberta as pessoas da desordem estabelecida? Em vez de orientados à adequação e integração a uma ordem que desmorona em todas as suas facetas (econômica, política, cultural, humanitária), mas cujos escombros são de corpos humanos, "derrubada" por um vírus tal como as formações sociais ditas não modernas que não resistiam às suas pragas, por que não buscar transformá-la? Por que não nos libertarmos dela? Em detrimento de uma remissão da nossa "nova" condição de vida - daquilo que viremos a ser depois que tudo isso passar - ao que éramos, por que não nos orientarmos para a construção do novo? Por que não nos forjarmos e, portanto, produzirmos saúde mental, numa ordem em que a humanização prevaleça à desumanização?

Com a mencionada reestruturação produtiva do capitalismo, cuja flexibilização e expansão mundializada reflete na ambiência cultural, tendo como consequência a compressão do espaço-tempo, temos a aceleração da dinâmica de vida de tal forma que até o colapso - ou, pelo menos, os sinais dele - não vem mais a cavalo, mas de avião, como o exemplo da dispersão do coronavírus no país. Isso faz com que o próprio movimento do capitalismo de sanar suas contradições internas - e, portanto, a costumeira eficácia do sistema em se autopreservar - não seja rápido o suficiente, em certos momentos; abrem-se brechas para a transformação radical dessa sociabilidade.

Assim, a crise como "situação-limite", sendo um aguçamento das próprias contradições internas do sistema, tende a tornar mais evidentes tais antagonismos, oferecendo oportunidades para se romper com suas amarras (Martín-Baró, 1984/2017a). Ao se produzirem de forma crítica, determinado período ou contexto histórico e seus elementos acabam por trazerem consigo, dialeticamente, suas soluções. Isso nos remete a Marx (1859/2008), para 
quem a "humanidade não se propõe nunca senão os problemas que ela pode resolver, pois, aprofundando a análise, ver-se-á sempre que o próprio problema só se apresenta quando as condições materiais para resolvê-lo existem ou estão em vias de existir" (p. 48). É no entrechoque do passado e do futuro no presente que emanam as crises, alargando as fissuras que podem muito bem ser suturadas, como também podem, a partir da ação humana, ser as fendas pelas quais abrolha o novo.

Optamos pelo caminho de discorrer acerca dos princípios e horizontes, os fundamentos, pois entendemos que o como é consequência destes pressupostos, a sua continuidade e operacionalização; que, em vez do como, devemos nos preocupar mais com o em benefício de quem este "como" se volta. Da mesma forma, não se deve centrar no onde, mas no a partir de quem; e, em vez de se preocupar em demasia com o tipo de atividade que se faz, devemos voltar nossas atenções para as consequências concretas que tais ações terão (Martín-Baró, 1996). Além do mais, a própria realidade, considerando as especificidades dos contextos, singularidades dos indivíduos, direcionará a esse como. Trazendo Martín-Baró para o nosso contexto, apenas ressaltamos que a complexidade do panorama vivenciado põe como desafio e necessidade, não se limitar "a atender os destroços e transtornos ocasionados pela guerra [no nosso caso, pelos vírus e crises capitalistas]; o desafio reside em construir um homem novo em uma sociedade nova" (Martín-Baró, 1984/2017a, p. 268). Esses novos ser e sociedade produzirão nova saúde mental, com seus novos problemas e especificidades, aos quais devemos produzir novas interpretações, conhecimentos, formas de agir - em suma, práxis, não cabendo futurologias idealizadas.

Em outro texto, mais antigo, com anotações que serviram de referência para uma palestra sobre o papel do psicólogo no processo revolucionário vivenciado em El Salvador, Martín-Baró (1980/2017b) apregoa a premência de se ser "um bom psicólogo" e, complementarmente, um "psicólogo do povo". Não vivemos um processo revolucionário, apesar de que, como expusemos anteriormente, as crises podem convergir para um - assim como à restauração da ordem - a partir da ação humana. Apesar das diferenças, as similitudes de situações-limite do agora pandêmico e crítico estado das coisas, com o igualmente crítico cenário da pandemia da guerra vivido por Martín-Baró, fazem com que as reflexões e sinalizações baronianas sobre o que deve ser a práxis de um bom psicólogo permaneçam de grande valia, indo além da psicologia, inclusive:

O psicólogo terá que antecipar os problemas que surgirão com a finalidade de facilitar e humanizar a passagem à nova sociedade. No curto prazo, terá que atender os 'traumas' do conflito e da desintegração social. A médio e longo prazos, deverá colaborar na edificação social de um homem novo, baseado em necessidades menos individualistas e em objetivos que partem da justa solidariedade (Martín-Baró, 1980/2017b, p. 26).

Finalmente, se a pandemia da covid-19 diz mais da sociedade na qual se alastra, não sendo capaz de lidar com ela, seu vírus e todas as suas consequências, é necessário pensar no tratamento dessa sociedade enquanto se trata daqueles(as) acometidos(a) pela doença e se busca prevenir o contágio de outros. No que se refere à saúde mental, ainda mais no contexto de coronavírus, mas não só nele, que o atendimento às demandas urgentes e imediatas não ocultem o que, de fato, precisa também ser tratado: a sociedade. "E o tratamento da sociedade se chama revolução" (Martín-Baró, 1973, p. 204). 


\section{Considerações Finais}

Foi necessária uma pandemia para evidenciar a muitos(as) que o problema era, justamente, a normalidade. A resposta do sistema era óbvia: voltemos a ela. O sistema produz a normalidade; esta é o sistema. Adaptemo-nos a ela. Ou deixemos que ela nos adapte. $\mathrm{Na}$ melhor das hipóteses de mudança, mudemos para que a ordem se mantenha. O que não se diz é que, como construção histórica, mistificada como natural, tornada como estática e dada, a normalidade se movimenta e se dinamiza. Seu "progresso" tem significado cada vez mais a normalização da anormalidade, incorrendo numa aceitação do que é inaceitável: a civilização da barbárie, pois, quanto mais avança a normalização do anormal, mais anormalidade e anormais ela produz, afinal, aos indivíduos é requerido que se adaptem a algo cada vez mais inadaptável. No caso aqui analisado, mais sofrimento é produzido.

Será que o novo normal pós-coronavírus será o isolamento social hiperbólico? Uma quarentena permanente, física e subjetiva? Se sim, até quando aguentaremos? Não questionamos a necessidade do isolamento como medida de contenção do coronavírus. Mas de uma sociabilidade que produz individualização e isolamento de um ser que é social e nela se assenta. Nesse caso, qual é o aumentativo de pandemia? Qual é o superlativo da hipérbole? Qual a capacidade de perdurarmos, enquanto seres sociais, nessa lógica ultraindividualizante e, portanto, desumanizante, que nos nega justamente aquilo que nos faz humanos?

Assim, em vez de um horizonte que avança apontando para trás, um Curupira que, ao andar para frente, leva-nos a acompanhá-lo ao passado, faz-se necessária, mais do que nunca, uma utopia realista (e aqui não existe contradição). Um forjar do novo assentado em um realismo crítico; da necessidade de mudança que nos indica a nossa própria condição presente de existência. A dialética do negativo, em que o que somos traz consigo o que não somos, levando-nos a criar o que podemos - e devemos - ser, conforme postulou MartínBaró (1983/2017c). A isso devemos nossa saúde mental, pois é nesse interregno que se porá nossa constituição como seres. Não fazendo isso, o plano de discussão pode, já no futuro próximo, deixar de ser sobre se ela será boa ou má, saudável ou mórbida, para se haverá saúde mental.

\section{Referências}

Barbosa, R. J., Prates, I., \& Meireles, T. O. (Coord.). (2020). Covid-19: Políticas públicas e as respostas da sociedade. A vulnerabilidade dos trabalhadores brasileiros na pandemia da Covid-19. Rede de Políticas Públicas \& Sociedade, nota técnica n. 2. Recuperado de https:// fpabramo.org.br/wp-content/uploads/2020/04/Boletim_2_Covid19__NT2v3.pdf

Batista, A., Antunes, B., Faveret, G., Peres, I., Marchesi, J., Cunha, J. P., . . Bozza, F. (2020). Análise socioeconômica da taxa de letalidade da COVID-19 no Brasil. Núcleo de Operações e Inteligência em Saúde (NOIS), nota técnica n. 11. Recuperado de: https://drive.google. com/file/d/1QKOUnUGE6IgoliM805Gp_CvvN9uD_ROi/view

Dardot, P., \& Laval, C. (2016). A nova razão do mundo: Ensaio sobre a sociedade neoliberal. São Paulo: Boitempo.

Fanon, F. (2015). Os condenados da terra. Juiz de Fora: Editora UFJF. (Obra original publicada em 1961). 
Fernandes, F. (2006). A revolução burguesa no Brasil: Ensaio de interpretação sociológica. Rio de Janeiro: Globo. (Obra original publicada em 1975).

Instituto Socioambiental. (2020). COVID-19 e os Povos Indígenas. Recuperado de: https:// covid19.socioambiental.org/

Lacerda Júnior, F. (2017). Colocando a Psicologia contra a ordem: Introdução aos escritos de Ignacio Martín-Baró. [Apresentação]. In I. Martín-Baró, \& F. Lacerda Júnior (Orgs), Crítica e libertação na Psicologia: Estudos psicossociais (pp. 7-21). Petrópolis: Vozes.

Marini, R. M. (2017). Dialética da dependência. Germinal: Marxismo e Educação em Debate, 9(3), 325-356. (Obra original publicada em 1973).

Martín-Baró, I. (1973). Antipsiquiatria y antipsicoanálisis. Estudios Centroamericanos - ECA, 28(293/294), 203-206.

Martín-Baró, I. (1996). O papel do psicólogo. Estudos de Psicologia, 2(1), 7-27.

Martín-Baró, I. (2011). Para uma psicologia da libertação. In R. S. L. Guzzo, \& F. Lacerda Jr., F. (Orgs.), Psicologia social para América Latina: O resgate da psicologia da libertação (pp. 101-120). Campinas: Alínea. (Obra original publicada em 1986).

Martín-Baró, I. (2017a). Guerra e Saúde Mental. In I. Martín-Baró, Crítica e libertação na Psicologia: Estudos psicossociais (pp. 251-270, F. Lacerda Júnior, Trad.). Petrópolis: Vozes. (Obra original publicada em 1984).

Martín-Baró, I. (2017b). O psicólogo no processo revolucionário. In I. Martín-Baró, Crítica e libertação na Psicologia: Estudos psicossociais (pp. 25-29, F. Lacerda Júnior, Trad.). Petrópolis: Vozes. (Obra original publicada em 1980).

Martín-Baró, I. (2017c). Entre o indivíduo e a sociedade. In I. Martín-Baró, Crítica e libertação na Psicologia: Estudos psicossociais (pp. 101-161, F. Lacerda Júnior, Trad.). Petrópolis: Vozes. (Obra original publicada em 1983).

Marx, K. (2006). Sobre o suicídio. São Paulo, SP: Boitempo. (Obra original publicada em 1846). Marx, K. (2008). Contribuição à crítica da economia política. São Paulo: Expressão Popular. (Obra original publicada em 1859).

Marx, K. (2010). Crítica da filosofia do direito de Hegel. Introdução. K. Marx, Crítica da filosofia do direito de Hegel (pp. 145-158). São Paulo: Boitempo. (Obra original publicada em 1844).

Marx, K. (2011). O 18 de brumário de Luís Bonaparte. São Paulo: Boitempo. (Obra original publicada em 1851).

Marx, K. (2017). Miséria da filosofia. São Paulo: Boitempo. (Obra original publicada em 1847). OXFAM Brasil. (2020). Tempo de cuidar. O trabalho de cuidado não remunerado e mal pago e a crise global da desigualdade. Cidade: OXFAM Brasil. Recuperado de https://oxfam.org. br/justica-social-e-economica/forum-economico-de-davos/tempo-de-cuidar/

Paulo Netto, J. (2012). Crise do capital e consequências societárias. Serviço Social \& Sociedade, (111), 413-429.

Recebido em: 09/06/2020

Última revisão: 20/07/2020

Aceite final: $21 / 07 / 2020$ 


\section{Sobre os autores:}

Pedro Henrique Antunes da Costa: Doutor em Psicologia. Professor da Graduação em Psicologia da Universidade de Brasília (UnB). E-mail: phantunes.costa@gmail.com. Orcid: https://orcid.org/0000-0003-2404-8888

Kíssila Teixeira Mendes: Doutoranda e mestre em Psicologia pela Universidade Federal de Juiz de Fora (UFJF). Bolsista CAPES. E-mail: kissilamm@hotmail.com. Orcid: https://orcid.org/0000-0002-7817-599X 
